\title{
VIOLÃO "ERUDITO" E "POPULAR" COMO \\ MARCADORES SOCIAIS DA DIFERENÇA - POR UMA HISTÓRIA DAS SUAS APROPRIAÇÕES PEDAGÓGICAS E ESTÉTICAS
}

\section{"CLASSICAL" AND “POPULAR" GUITAR AS SOCIAL MARKERS OF DIFFERENCE - FOR A HISTORY OF THEIR PEDAGOGICAL AND AESTHETIC APPROPRIATIONS}

\author{
Fernando Elías Llanos \\ Universidade de São Paulo \\ fllanos@usp.br
}

\begin{abstract}
Resumo
presente artigo propõe analisar as tensões entre a comunicação musical - entendida como dispositivo aglutinador e mediador de trocas simbólicas (SEINCMAN, 2008) - e as apropriações da cultura (popular e erudita) que, desde o cenário das práticas pedagógicas e das linguagens estéticas musicais vem definindo a práxis e o corpus teórico do ensino - nos níveis profissionalizante e superior - do violão.

Palavras-chave: violão popular; violão erudito; práticas pedagógicas do ensino do violão

Abstract

This article aims to analyze the tensions between musical communication - (as an unifying device and mediator of symbolic exchanges (SEINCMAN, 2008) - and the appropriation of both popular and clas-
\end{abstract}


sical cultures that in the setting of pedagogical practices and musical aesthetic languages has defined the practice and theory of teaching - either in vocational level or in superior guitar courses.

Keywords: popular guitar; classical guitar; the guitar teaching practices

\section{Percurso da problemática}

No transcurso de dois anos de observações empiricas constatou-se a crescente demanda de cursos de ensino de música popular e, especificamente, de cursos para a formação em violão popular, em diversas instituições de ensino superior (IES) - públicas e privadas assim como em escolas livres com cursos profissionalizantes regulados pela Secretaria da Educação de governos locais (no caso, municípios que integram a Grande São Paulo). Nesta fase, observou-se que os locais de ensino têm uma série de lacunas metodológicas, teóricas e práticas na hora de elaborar uma proposta formal - nos parâmetros de uma ementa curricular - para o ensino do instrumento.

Na orientação da sua performance musical e na fundamentação dela como prática musical, a profusão de referências assim como sua diversidade de origens constituem seu traço mais característico. Outro ponto a destacar foi a forte influencia da linguagem musical jazzística, escola estadunidense presente através do vasto corpus metodológico para o ensino!. Na maioria desses casos existe uma deliberada vontade de associar o conceito de popular ao conceito de standard, como num esforço de estabelecer o cânone do jazz como sendo a alternativa mais teórica e fundamentada, no quesito de me-

\footnotetext{
I Para as referências teóricas Cf.: RAULLINS, Robert e BAHHA, Nor Eddine. Jazzology: the encyclopedia of jazz theory for all musicians. Milwaukee, Wl: Hal Leonard, 2005. Para as referencias técnicas Cf. AEBERSOLD, Jamey. How to Play Jazz and Improvise. Vol. 1. Indiana: Jamey Aebersold, 1967; BAKER, David. David Baker's Jazz Improvisation: A Comprehensive Method for All Musicians. California: Alfred Music, 1988; COKER, Jerry. Improvising Jazz. Nova York: Simon and Schuster, 2010.
} 
todologia, que possa "fazer frente" à tradição erudita (HOBSBAUM, 1996, 177-190). Em outros casos, o popular é o brasileiro², e neste caso se faz referência a um leitura do repertório assim chamado folclórico, muitas vezes com técnicas - na performance e na composição musical - vindas do repertório clássico europeu. Tudo isso denota, em parte, um momento de transição no ensino do instrumento, e também uma das fases mais pertinentes para levantar questionamentos que contribuam para o levantamento de um corpus teórico e prático para pensar possiveis alternativas na elaboração de um modelo ${ }^{3}$ de projeto pedagógico.

\section{Abordagens teóricas na definição do popular}

No levantamento das questões teóricas e conceitos que atravessam as práticas pedagógicas e a performance musical, desde já podemos destacar as diversas definições de cultura popular. Temos perspectivas que a apresentam como a "inversão do estabelecido", como no caso da cultura carnavalesca, em Bakhtin (apud ZUBIETA, 2004, 29), que propõe uma visão do homem e das relações humanas deliberadamente distintas da oficial (entendendo o oficial como a lgreja e o Estado), onde a lógica imperante é a subversão radical dos valores, hierarquias, normas e tabus religiosos, políticos e morais em prática, num sentido tanto destrutivo quanto regenerador de ciclos e estações que se sucedem. Desta maneira, a cultura popular, nos moldes da transgressão, relativizaria a verdade $e$ as autoridades dominantes.

2 Uma análise da noção de popular também se faz necessária em relação à lei no 3.857 , de 22 de dezembro de 1960, quando a criação da Ordem dos Músicos do Brasil e a disposição sobre a regulamentação do exercício da profissão de músico.

${ }^{3}$ Ao falarmos em modelo nos referimos a um conjunto de definições provisórias elaboradas a partir de hipóteses sobre aquilo que consideramos viável (possivel, mas relevante) enquanto ensino do instrumento e seu repertório. Dito de outra forma trata-se de uma proposta cujo objetivo final é elucidar a importância dos diálogos entre a teoria e a prática, contextualizados na história social do instrumento. De nenhuma forma pretendese "validar cientificamente" o cânone musical que proponha uma única fórmula estética do que "deva" ser estudado por considerá-lo um conjunto de obras, no sentido museológico do termo. 
Outros teóricos como Burke (Idem, 32) apontam a noção de cultura popular como ponto-chave da história de uma sociedade, entendida como uma complexa rede de trocas entre a alta e a baixa cultura, assim como outras fragmentações sistemáticas (letrada ou popular, grande ou pequena tradição, sub-cultura, contracultura).

Também é possivel repensar o conceito de cultura popular em e através do conceito de hegemonia em Gramsci (Id.,38), definindo-o como um sistema de relações entre classes sociais que configura um lugar da produção de consenso, mas também de resistência ao consenso. Outras categorias como apropriação, em Ginzburg e Chartier (ld., 46), são centrais no estudo atual da cultura popular, onde os empréstimos, traduções, transformações e reduções tanto podem acontecer da alta cultura (ou cultura letrada) para a cultura popular, como vice-versa, num processo que não deixa de produzir a tensão própria da luta ${ }^{4}$.

Geertz (1978), por sua vez, redefinindo o objeto e propondo uma análise da cultura como ciência interpretativa à procura de significações, reformula a teoria com seu conceito semiótico da cultura, convidando a entender o entrecruzamento de estruturas complexas,

\footnotetext{
${ }^{4}$ Trazendo a tensão da luta entre o popular e o erudito, acre ditamos que esta divisão constitui uma falsa dicotomia toda vez que a diferença entre ambas é produzida e demarcada com fins políticos de exclusão social de determinado projeto estético. Tanto o popular como o erudito é definido por consenso (institucional), consagrado pela prática (como, por exemplo, na estrita observância de um cânone), ensinado como obrigatório (pelos professores) e veiculado como referência cultural (pelos méios de comunicação). Nesse sentido, um curso de violão que dialogue com as práticas e teorias da tradição clássica europeia, do jazz e da tradição violonística brasileira seria o ideal. Contudo, um projeto pedagógico amplo também deve contemplar a especialização como inerente à formação técnica do violonista. Assim, o erudito e o popular poderiam ser campos de exercício profissional que partem de uma escolha individual e não mais desta espécie de "incisão epistemológica" institucionalizada, que forma violonistas "diferenciados".
} 
sem reificar ${ }^{5}$ algum dos seus componentes e colocando-os fora de relações do tipo causa-efeito. A prática deste enfoque critica duramente a compreensão do homem e sua cultura como uma somatória de vários niveis ou "capas", pois somente seria possivel - no melhor dos casos - estabelecer analogias, paralelismos, sugestões e afinidades, nunca relações entre fatores culturais e não culturais.

Outra aproximação, em Bordieu (ORTIZ, 1983, 99), que faz leituras do estilo de vida e a divisão social de classes, entende o culto à "cultura popular" como a própria ratificação de certo desapossamento cultural onde esta última constitui uma dimensão privilegiada. Assim, o estilo de vida e a disposição estética das classes populares devem suas caracteristicas fundamentais - e supondo nisso uma vantagem positiva - ao fato de representar uma forma de adaptação à posição ocupada na estrutura social e, de certo modo, um reconhecimento dos valores dominantes.

Até aqui, entre as diversas linhas de pensamento sobre cultura popular e o "popular", analisadas desde a história, a antropologia e sociologia, acrescentamos uma que consideramos importante e que não parece ter sido discutida nas definições acima resenhadas: a construção do mito da "ingenuidade perdida".

Por mito da "ingenuidade perdida" entende-se o processo so-

\footnotetext{
${ }^{5}$ Termo cunhado pelo teórico literário e filósofo húngaro Georg (György) Lukács ( 1885 1971) que é uma extensão da análise do conceito de fetichismo da mercadoria, discutido pelo filósofo Karl Marx (1818-1883) no seu livro $\bigcirc$ Capital (1867). Reificar é alienar o processo da criação (intelectual) ou a manufatura e/ou oferta de um produto (um alimento, um objeto, uma propriedade imóvel, qualquer bem no sentido amplo do termo) do plano físico e social que o produz, tornando-o um outro "sujeito" (outro bem em geral) avaliado quantitativa e qualitativamente independente do seu valor de fato (isto é, avaliado subjetivamente, especulado por qualquer motivo), e até mesmo desvinculado da sua origem. A teoria da reificação, como resultado de uma patologia induzida socialmente, teve uma considerável influencia na chamada Escola de Frankfurt, principalmente no seu mais destacado membro, o filósofo Theodor W. Adorno (1903-1969). Verdinglichung é o termo em alemão cuja tradução guarda o sentido latino de res (coisa), que poderia ser traduzido como coisificação.
} 
cial no qual a cultura - humana, no singular - tem institucionalizado uma comunicação complexa que define a sua própria utopia e sua respectiva realidade. Nela é possivel experimentar o fenômeno da "aura do popular", associada ao "natural", ao "verdadeiro", ao ingênuo, ao espontâneo, à infância (DE CERTAU, JULIA, 1989, 57) de forma que tanto vale pela sua pretensa espontaneidade como pela sua importância como patrimônio histórico e geográfico de determinada sociedade.

No popular pressupõe-se um "começo originário" da literatura - pois é sinônimo da oralidade como pré-textualidade - e a infância da cultura, a mesma que deve ser incessantemente preservada e reencontrada. Igualmente, o referido mito está presente no histórico datado e documentado de etnólogos e arqueólogos - fiscais "da essência" do passado - precedidos no tempo só pela prática do antiquário - herdeiro do maneirismo literário - e a do folclorista - guardião da tradição (ORTIZ, 1993). Como um indígena rousseauniano, a alma popular seria incapaz de distorções, pois ela condensa as qualidades de uma "inocência" esquecida.

\section{Arquétipos do violão erudito e popular}

Muito pode ser falado da história do instrumento e da variedade de intérpretes e apropriações que o violão teve no Brasil. Poucos países no mundo contam com uma produção prolífica $e$ uma massiva familiaridade. A importância do estilo "voz e violão" para o gênero canção assim como as diversas técnicas locais do instrumento e sua própria função social fazem do país um objeto de estudo privilegiado. Depois de Espanha, países como Cuba e Brasil são referência obrigatória nos estudos musicológicos do violão no século XX, a julgar por nomes como Leo Brovwer e Heitor Villa-Lobos. Precisamente, a riqueza dessas duas verdadeiras escolas violonísticas jaz na sua natureza fronteiriça: no limiar gigantesco do que se convencionou em chamar de erudito e popular, isto é, o seu "lugar de fala" é bem no meio dessa tensão e jamais em lados opostos. Em linhas gerais, pode se dizer que 
a América Latina contribuiu para renovar a estética e a metodologia do instrumento, cuja escola de tradição europeia nunca antes tinha experimentado tal revolução de repertório e desafios físico-instrumentais.

Contudo, atualmente o ensino profissional do instrumento adotou o discurso das belas artes, que entende a música -entre outras expressões- como: "matéria de inspiração e genialidade e, por isso mesmo, objeto de desfrute específico, mediado por um prazer refinado, enquanto os artesanatos $e$ as artes populares tornaram-se práticas que mostram a habilidade do artífice na aplicação de certas regras e cujas obras, ainda, são concebidas meramente para serem usadas ou para entreter ao público" (SHINER, 2004, 24 - tradução minha).

Toda bela arte também escolhe seu próprio museu para a posteridade, o cânone: "A eleição do cânone é resultado de uma "política da memória' cujas escolhas influem diretamente nas condições de circulação e recepção das obras, definindo sua permanência no mercado, nas bibliotecas e nos horizontes de expectativa do público (CINZBURC apud CÂMARA, 2013, p. 48). São esses interesses hegemônicos que precisam ser contestados no espaço criador de legitimidades que é a sala de aula."

Do convívio entre a natureza fronteiriça da performance violonística e sua cultura e institucionalização pelas belas artes, surgiram diversos arquétipos no Brasil e no mundo, que exemplificam diferentes nuances da noção de popular.

Temos o "popular" Baden Powell: possuidor de um leque de influências musicais que iam de Bach, passando por Pixinguinha e os clássicos do jazz, nos termos de Bakhtin, ele representa uma "carnavalização" da técnica erudita para o violão e a subversão dos padrões da performance oficial. Nele contava mais a veia musical comunicativa, o "duende" como diriam os espanhóis. Criticado por ter uma interpre- 
tação "suja", Baden é um divisor de águas na música brasileira e na literatura do instrumento (CALILEA, 2012, 157).

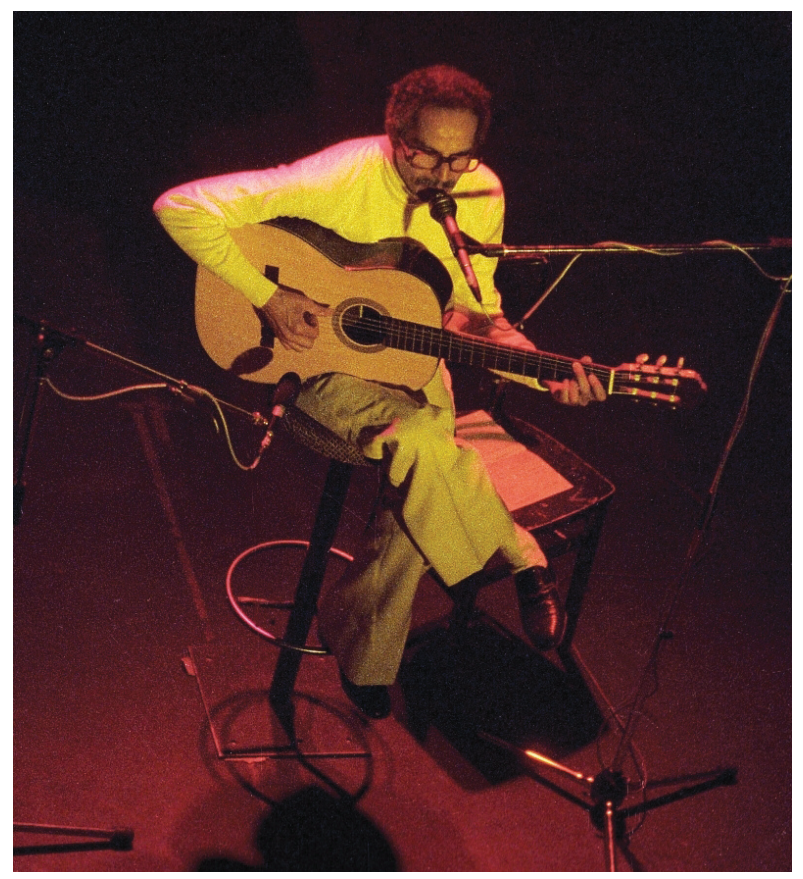

Figura 1: Baden Powell (1937-2000). Disponivel em https://upload.wikimedia.org/wikipedia/commons/O/Ob/Baden-powell-de-aquino-img92-small.jpg

De outro lado, temos a performance erudita "mas" com inspiração "popular": na obra de Villa-Lobos, os diálogos entre a música de concerto, a música de salão e a música de rua (leia-se choros e outros ritmos) eram os pilares do seu trabalho composicional. Nos termos de Burke, Villa-Lobos seria um ponto-chave na história da música brasileira, que desenvolveu intensas trocas desde as altas culturas do violão

\footnotetext{
" No jargão da técnica violonística de tradição europeia, chamasse "sujeira" aos sons próprios do manuseio do instrumento (ex.: na passagem dos dedos da mão esquerda nas últimas cordas, quando acontece a troca de casa ou até mesmo na execução desmesuradamente forte da mão direita). A cobrança por um som "limpo", então, seria o estudo de diversas técnicas que evitassem ou mesmo eliminassem tais sons.
} 


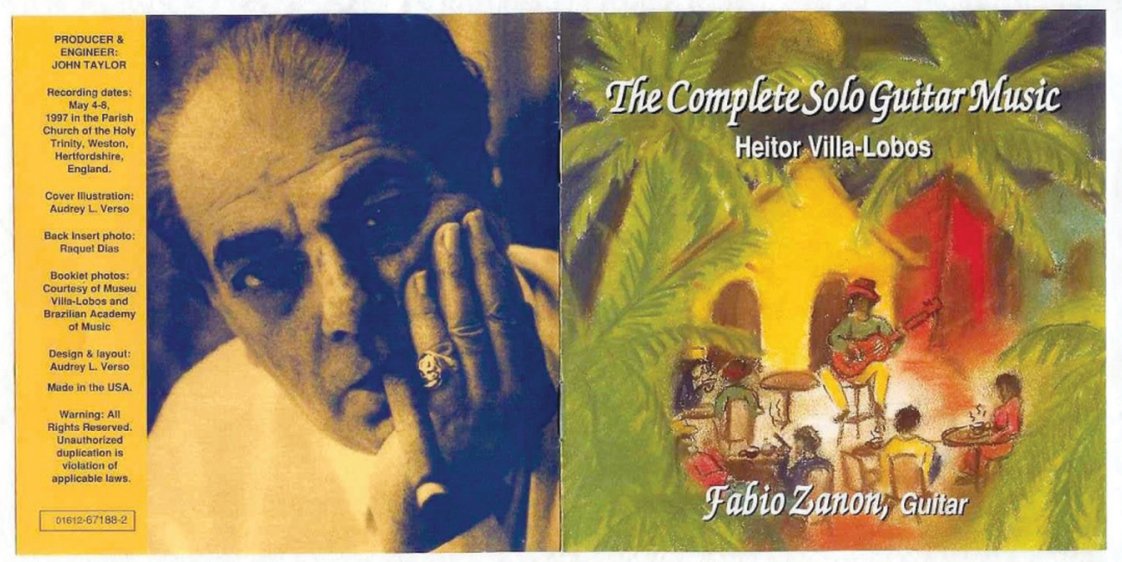

Figura 2: encarte do disco com a obra de Villa-Lobos para violão, e o apelo "exótico" da arte da capa. Disponivel em http://l.bp.blogspot.com/-P4eALdOuzQI/TXIsxI7MIQI/AAAAAAAAAwY/ejCGPzjC8ww/s I 600/Nilla-Lobos\%2B-\%2BComplete\%2BSolo\%2B Guitar\%2B\%2528Fabio\%2BZanon\%2529\%2B-\%2B00a\%2B-\%2BCD\%2BFront. .jpg (acessado em 16.12.2015).

Se o popular também é produto do consenso, por muitas décadas falar em violão era se referir ao "popular" maestro Andrés Segovia, quem entre violões flamencos e estudos de Sor e Tárrega (Idem, 97) trilhou seu próprio caminho das pedras. No sentido gramsciano, Segovia foi o grande consenso na história do violão e representante de uma das escolas mais hegemônicas e ainda vigentes do arquétipo da performance instrumental.

\footnotetext{
7 Uso o termo folclore apenas como sinônimo de popular na redação do presente artigo, mas não como conceito, pois, concordo com lkeda (2013) ao afirmar que este tem sido evitado "por seu desgaste semântico [...] pela maneira como os fatos culturais populares, tradicionais, foram concebidos, estudados e divulgados por muitos folcloristas: de modo descontextualizado, considerados apenas em aspectos fragmentados das expressões em si, nas suas exterioridades e formas, independentemente das suas funções e sentidos profundos para as pessoas e comunidades onde se preservam."
} 


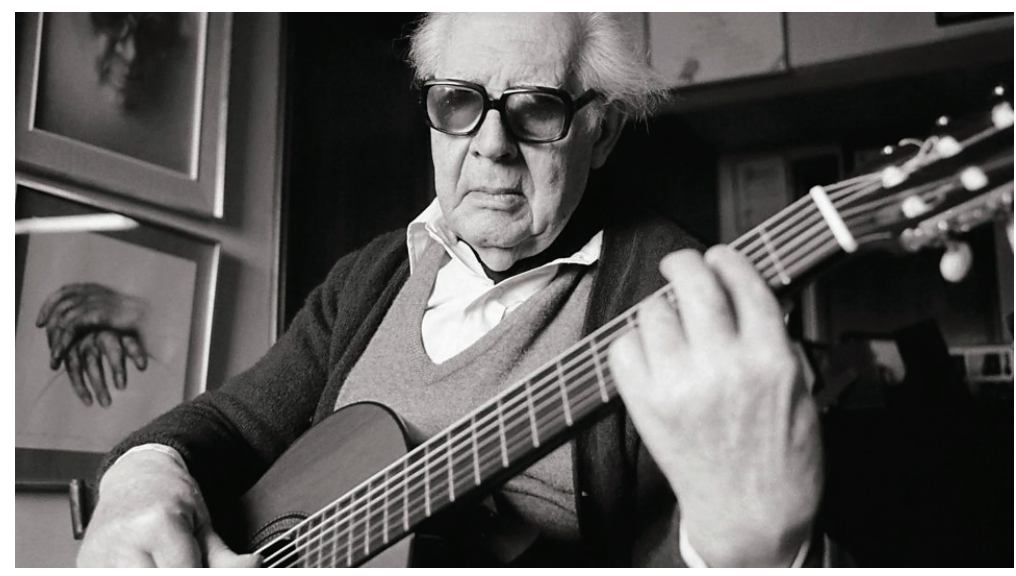

Figura 3: Andrés Segovia ( 893 - 1987). Disponivel em http://ichef.bbci.co.uk/images/ ic/960x540/p0 lbr5jw.jpg (acessado em 16.12.2015).

A leitura das relações do triangulo popular-fronteiriço-erudito também pode ser entendida através do apelo estético do exotismo ${ }^{8}$. A exemplo, podemos mencionar duas figuras de meados do século passado: a de Carmem Miranda com seu cesto de frutas sobre a cabeça, e a de Yma Súmac e seu trajado "incaico". Ambas foram dois ícones latino-americanos que floresceram na estratégica abertura cultural de Estados Unidos, e de Nova York como berço das culturas do mundo pós-segunda guerra mundial. Muito antes que as cantoras acima mencionadas, o paraguaio Agustín Barrios já compunha e executava o violão com peculiar virtuosismo, mostrando ao mundo seu lirismo de cacique indigena guarani (ldem, 107).

\footnotetext{
8 Exótico não como adjetivo pejorativo (que contrasta o belo, o refinado, o sofisticado com o exótico enquanto bárbaro, selvagem) e sim como categoria estética e até mesmo recurso extra-musical para fins de divulgação. Afinal de contas, o concerto de violão na carreira de um violonista não é um evento religioso e sim uma empreitada profissional e comercial.
} 


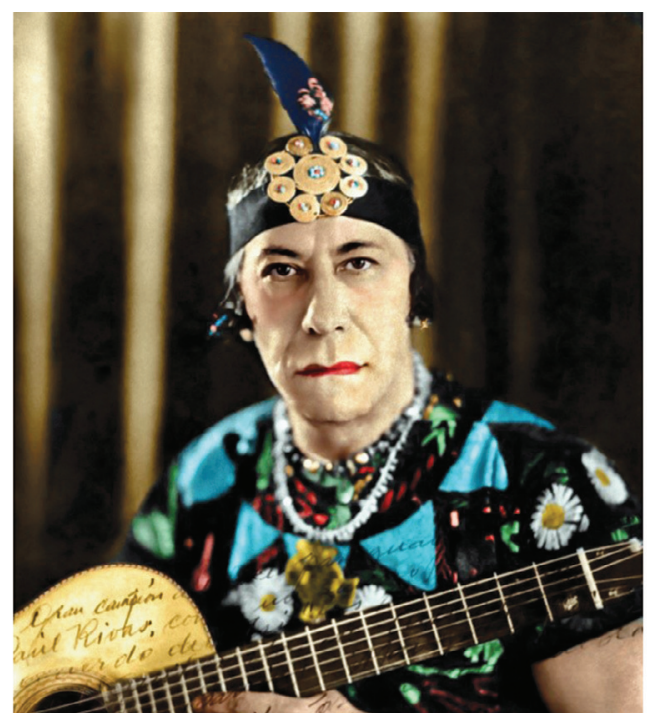

Figura 4: Agustín Pio Barrios Ferreira, "Mangoré" ( 885 - 1944). Disponivel em http://martinwullich.com/wp-content/uploads/20 I I/09/foto2622.jpg (acessado em 16.12.2015).

Saindo do exotismo de apelo étnico, passamos a outro exotismo do tipo tecnicista, este se considerarmos o violão de 6 cordas como sendo o "normal". Me refiro ao exótico violão de 14 cordas de Egberto Gismonti, o mesmo que estabeleceu também uma prolífica carreira como compositor e instrumentista, desenvolvendo uma linguagem particular naquela região da tríplice fronteira: o erudito, o popular, e "aquilo" no meio - produto de ambas. 


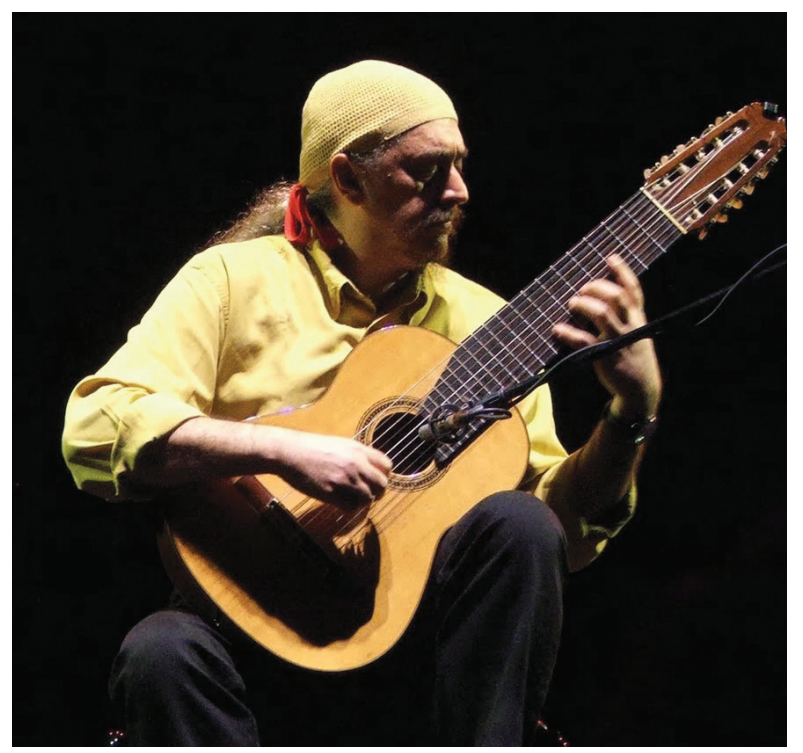

Figura 5: Egberto Cismonti Amin (1947). Disponivel em http://h3.googleusercontent com/-BmjFxU5g7rA/UxL4K8cMwhl/AAAAAAAAO6g/5GgkNOSc3H8/d-lc42/Egberto\%252520Gismonti\%2525202005_1211_020.JPG (acessado em 16.12.2015).

Mas, e se além de escolas violonísticas que subvertem o estilo "limpo" (Powell), de obras inspiradas nos chorões9 da rua (Villa-Lobos), de instituições hegemônicas produtos do consenso (Segovia), e de exotismos étnicos (Barrios) e técnicos (Cismonti), se inventasse um discurso totalizador que, na sua proposta, integre todo e qualquer gênero musical e dilui-se qualquer fronteira de formação, técnica e performance? Longe dos dicionários e das resenhas academicas, o violonista brasileiro Robson Miguel desenvolve uma vida paralela, longe dos holofotes da discussão "oficial" e "séria" sobre o violão no país. Autointitulado como Mestre Robson Miguel, o músico se divulga ${ }^{10} \mathrm{como}$ erudito, popular, pop, jazzístico, e o que vier pela frente. Além disso,

\footnotetext{
9 Jargão para músicos dedicados ao choro.

${ }^{10}$ Cf.: MICUEL, Robson. "Biografia". Sitio de internet de Robson Miguel. Disponivel em http:// www.robsonmiguel.com.br (acessado em 21.07.20 14). // Confrontar também: MICUEL, Robson. Robson Miguel. In: Dicionário Cravo Albin da Música Popular Brasileira. Disponível em http://www.dicionariompb.com.br/robson-miguel (acessado em 21.07 .2014 ).
} 
tem produzido uma série de vídeo-aulas para iniciantes no violão, viola caipira, violino, cavaco, e outro sobre regência para coro e orquestras. É conhecido por ter um violão de série dedicado a ele ("violão Firmino série Mestre Robson Miguel"), por produzir um encordoamento criado por ele ("cordas de violão diferente"), pelas suas constantes e repetidas aparições em programas de TV aberta (principalmente no programa do Jo Soares) e por construir e morar num castelo que ele mesmo batizou de Castelo de Robson Miguel. Na sua autobiografia, são constantes as autorreferências sobre seu protagonismo internacional representando ao Brasil e, mais recentemente, sua luta pelas causas indígenas"l.

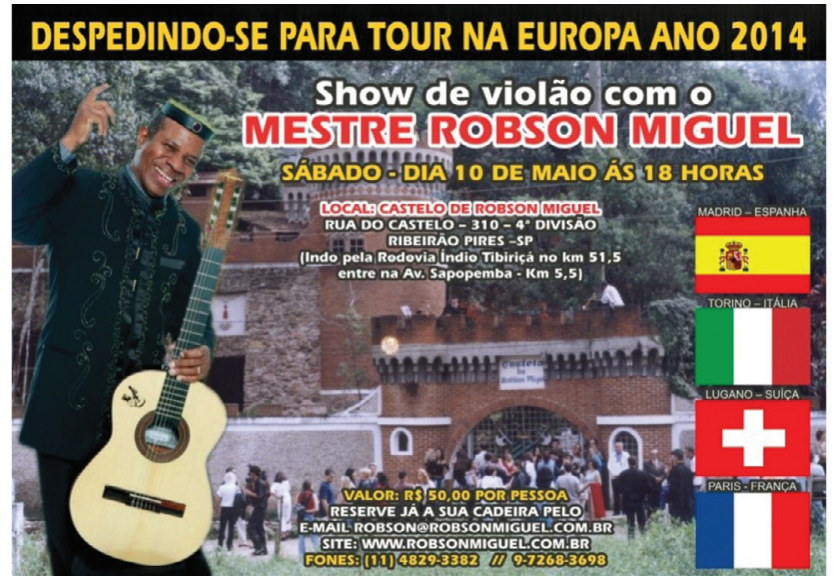

Figura 6: cartaz de divulgação da turnê mais recente.

No fundo, visitantes do seu castelo. Disponível em http://gaiabrasil.com.br/20 1 4/05/robson-miguel-faz-show-antes-de-tournee-violao/ (acessado em 21.12.2015).

\section{Conclusão}

A discussão sobre as diversas noções do popular, nas suas va-

\footnotetext{
"I Foi nomeado cacique numa Aldeia de Itaóca (Mongaguá-SP) e casou com uma índia tikuna.
} 
riadas apropriações e no ensino do violão, foi o início de uma série de indagações que mostraram como é insuficiente e insatisfatória qualquer tentativa metodológica que pretenda diferenciar ou mesmo igualar o popular e o erudito. Estas primeiras reflexões não fizeram senão revelar o grau de complexidade ao definirmos "o popular" seja como repertório, como performance ou como plano de formação profissional, sendo que devemos considerar as particularidades de diversas linguagens musicais que, na sua própria autodefinição, também dialogam com a prática e a técnica composicional erudita.

Noutro extremo, casos como os do violonista Robson Miguel parecem ser concebidos numa espécie de autossuficiência $e$ indiferença ao discurso oficial e institucional, cuja autonomia deve muito ao potencial massificador da Internet na última década. Além do mais, a pesquisa formal é um expediente para manter à distância os não-iniciados e faz parte do equipamento que anuncia o caráter sagrado, "separado e separador, da cultura legítima (BOURDIEU apud CÂMARA, $2010,570)$.

Contudo, dos diálogos entre o sistema das belas artes e os submundos que pairam seu discurso hegemônico também surgem figuras que podem ser descritas por um "caos criativo transerudito": na fronteira da world music e a técnica brouweriana, com a lógica mestiça do violão hispânico revisitado pela América Latina via o folk estadunidense de Ralph Towner. 


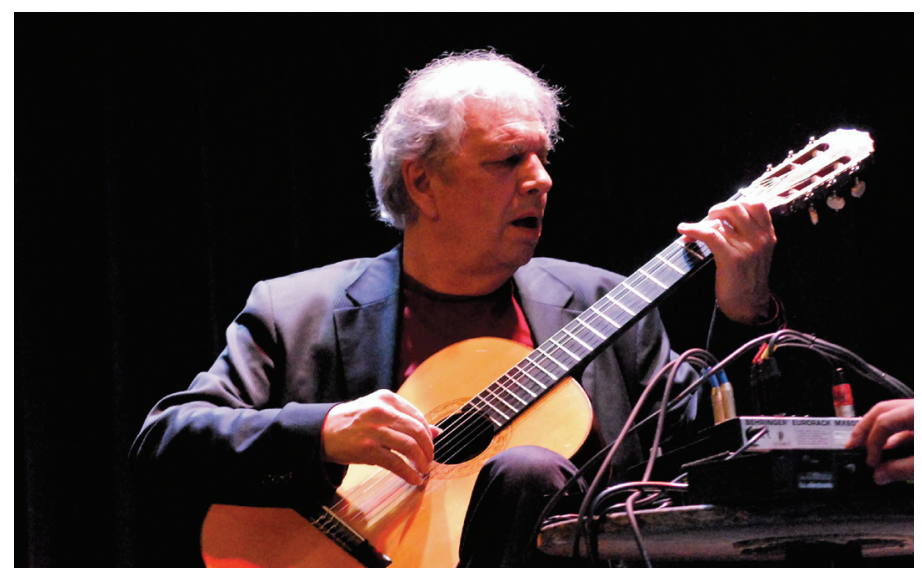

Figura 7: Ralph Towner (1940). Disponivel em https:/upload.wikimedia.org/wikipedia/commons/4/4f/Ralph_Towner.JPG (acessado em 16.12.2015).

músico estadunidense propõe revisitar a técnica do violão através de suas composições, as mesmas que transitam pelo universo do erudito (isto é, pela história das apropriações no instrumento) e que sugerem performances jazzisticas (com improvisações pensadas/ escritas anteriormente) em contraste às interpretações que seguem a risca a partitura. Ele também incorpora recursos técnicos próprios do estilo folk do seu país e que produzem um violão mais percutido, assim como a interação com outros instrumentos (um trio de jazz, por exemplo: bateria, piano, e baixo) mantendo sempre a técnica característica do ataque da mão direita (apoiando, tirando) e usando uma ampla gama de recursos tímbricos (quero dizer, analógicos, principalmente) próprios do instrumento. A escolha de Towner como sujeito que encarna certo ideal de síntese para a história do violão obedece também a um critério de pertinência e atualidade: entre muitos violonistas eruditos e populares pesquisados e/ou admirados poucos possuem ao longo da sua produção elementos dissimiles que tem congregado distintas escolas violonísticas e estão longe de polarizar as posições do erudito e o popular.

Por tudo isso, pensar nas histórias que produziram a divisão 
entre o popular e o erudito no violão significaria, principalmente, evidenciar a construção de marcadores sociais da diferença no contexto atual das culturas de massa e a globalização. Assim, resulta importante desvendar como questões específicas decorrentes das categorias gênero (musical), estilo e performance são politizadas (ex.: via critérios de "prioridades" dos órgãos de fomento à pesquisa), normatizadas (em editais públicos) e institucionalizadas (pelas ementas das disciplinas e pela estrutura de cursos que integram uma graduação profissional) além de resignificadas pelos sujeitos afetados ${ }^{12}$.

\section{Referências}

CÂMARA, Marcos. Música erudita Contemporânea: valor estético e valor simbólico. Anais do XX Congresso da ANPPOM.V. único. Florianópolis, SC, 2010 . pp. 568-572.

Educação: o campo maior de aplicação da pesquisa em música. Anais do I Simpósio de Estética e Filosofia da Música. E-book. Porto Alegre: UFRGS, 2013. pp. 44-53.

DE CERTAU, Michel; JULIA, Dominique. "A beleza do morto: o conceito de cultura popular". In: REVEL, J. A Invenção da Sociedade. Lisboa: Difel, 1989.

FOUCAULT, Michel. A ordem do discurso. São Paulo: Ed. Loyola, 1996.

CALILEA, Carlos. Violão Ibérico. Rio de Janeiro: Trem Mineiro Produções Artísticas, 2012.

GARCÍA CANCLINI, Néstor. La sociedad sin relato. Antropología y Estética de la Inminencia. Buenos Aires: Katz Editores, 2010.

\footnotetext{
12 Neste caso refiro-me à recepção com as seguintes perguntas: como são percebidas e manejadas tais divisões? Como tem sido o convívio nesse "status quo" da formação e prática musical?
} 
CEERTZ, Cliffort. A Interpretação das Culturas. Rio de Janeiro: Zahar; 1978.

HOBSBAUM, Eric. Historia social do jazz. São Paulo: Paz e Terra, 1996.

RANGER, Terence. (Orgs.). A invenção das tradições. Rio de Janeiro: Paz e Terra, 1984.

IKEDA, Alberto T. Culturas populares no presente: fomento, salvaguarda e devoração. Estud. av., São Paulo, v. 27, n. 79, 2013.

SHINER, Larry. La invención del arte: una historia cultural. Barcelona: Paidós, 2004.

ORTIZ, Renato. Românticos e Folcloristas: cultura popular. São Paulo: Ed. Olho d'água, 1993.

(Org.) Pierre Bordieu: Sociologia. São Paulo: Ática, 1983.

SEINCMAN, Eduardo. Estética da comunicação musical. São Paulo: Via Lettera, 2008.

SEVERINO, Antonio Joaquim. A pesquisa em educação: a abordagem crítico-dialética e suas implicações na formação do educador. Revista Contrapontos, Itajaí, SC., v. 1, n. 1, p. 1 1-22, Jul. 2008. ISSN 1984-7 | 4.

SCHAFER, R. Murray. A afinação do mundo (a paisagem sonora) São Paulo: UNESP, 2001

STAHL, Titus, "Georg [György] Lukács", The Stanford Encyclopedia of Philosophy (Winter 2013 Edition), Edward N. Zalta (ed.), Disponivel em http://plato.stanford.edu/archives/win20 I 3/entries/lukacs (acessado em 27.02.2014).

TABORDA, Marcia. Violão e identidade nacional. São Paulo: Editora 
José Olympio, 2011.

ZANON, Fábio. O violão no Brasil depois de Villa-Lobos. Violão com Fábio Zanon, v. I, Brasilia: MRE, 2006.

ZUBIETA, Ana Maria (Org.). Cultura popular y cultura de masas: conceptos recorridos e polémicas. Buenos Aires: Paidós, 2004. 